\title{
A PAIXÃo PELAS FORMAS
}

\section{Gilda de Mello e Souza}

\author{
HELOISA PONTES
}

\section{RESUMO}

Com foco nos livros $O$ espírito das roupas e $A$ idéia e o figurado, este artigo procura analisar a trajetória intelectual da ensaísta Gilda de Mello e Souza (1919-2005). Mostra-se como a autora mobilizou fontes diversas, sejam do âmbito da história, da sociologia, da antropologia ou da estética, para compor uma obra rica em pontos de vista inesperados e avessa a academicismos, adensando o foco analítico sobre os objetos analisados.

PALAVRAS-CHAVE: Gilda de Mello e Souza; moda; estética; sociologia.

\section{SUMMARY}

Taking the books $O$ espírito das roupas e $A$ idéia e o figurado as a guideline, this article analyses the intellectual trajectory of Gilda de Mello e Souza (1919-2005). It shows how the author took advantage of a wide variety of sources, from history to sociology, from anthropology to aesthetics, to create a work full of insights and freedom of expression, and to sharpen her approach to the objects analysed.

KEYWORDS: Gilda de Mello e Souza; fashion; aesthetics; sociology.

(para Antonio Candido)

Em 1992,o pesquisador e estudioso de cinema Carlos Augusto Calil fez uma entrevista surpreendente com Gilda de Mello e Souza sobre o último filme de Luchino Visconti, Conversation piece. Essa entrevista foi ao ar pela TVA e teria permanecido nos arquivos da emissora não fosse a inclusão nos extras do filme em formato DVD, disponível no Brasil como Violência e paixão. Graças à iniciativa de Calil, os que não a conheceram pessoalmente e os que partilharam a companhia dela e a admiraram como mulher eintelectual poderão revê-la em um momento encantador. 
Sob um fundo vermelho vazado de branco, Gilda de Mello Souza destaca-se pela beleza e elegância. Vestida com um tailleur de tafetá branco perolado, blusa de seda da mesma cor com apliques em altorelevo e ligeiramente transparente no colo, calçando um escarpin bicolor, bege e marrom, Gilda usa como adereços um colar de pérolas e brincos que intensificam o prateado dos cabelos bem penteados. Como maquiagem, apenas o batom vermelho que irradia luz às cores discretas da vestimenta e aviva-lhe a fisionomia. Esse "elo de identidade e concordância" que ela cria com a vestimenta e que a tornou conhecida como mulher elegante, além de intelectual brilhante, é reforçado pelo movimento dos olhos nos momentos em que seu pensamento alcança vôo e ouvimos o tilintar discreto das pulseiras brancas que se movimentam pelos braços e dão às mãos a segurança dos gestos suaves.

De início um pouco retraída e ligeiramente desconfortável diante da câmera, Gilda vai ganhando a cena à medida que a entrevista avança e ela se torna senhora de si. Transitando com desenvoltura pela obra de Visconti, descortina dimensões inusitadas da personalidade do diretore do filme em tela. Conversation piece foi filmado em 1974, com os atores falando em inglês, quando Visconti já estava doente. Versa sobre um intelectual maduro e solitário, magistralmente interpretado por Burt Lancaster, que vê a intimidade invadida por um grupo ruidoso que gira em torno de uma condessa riquíssima evulgar, papel que coube a Silvana Mangano. Tocado pela sinceridade da filha da condessa e pela sensibilidade e beleza de seu jovem amante, interpretado por Helmut Berger, o professor será arrastado, a contragosto, num tumulto de paixões.

Recusando-se a sublinhar a dimensão política do filme, tal como ressaltada pelo entrevistador, Gilda propõe outra interpretação, lembrando-nos a posição de crítica. "Toda visão que nós temos de uma obra de arte é uma visão muito deformada pelo olhar do observador. Eu acho que a minha visão é muito deformada pela minha personalidade e pela minha personalidade apolítica, em muitos casos." Mas é justamente essa "deformação" que confere tônus à interpretação que ela faz do filme. A começar pelo que descortina do título, Conversation piece, alusão ao gênero pictórico das cenas domésticas e familiares da aristocracia, tão bem captadas na pintura inglesa. Transposto para a trama do filme, sinaliza "uma espécie de diálogo prolongado e aprofundado entre dois grupos de famílias", disparado pela intrusão da condessa e seus próximos no resguardo ciosamente cultivado pelo intelectual requintado. "O grupo de famílias que está petrificado nos quadros e, que, portanto, já foi deslocado para o mundo da arte" - no qual se reconhece o personagem central - e o "grupo da família desordenada, caótica e sem moral — pois pertence a um mundo de passagem -, que invade a casa do professor".

No conjunto da obra do diretor italiano, prossegue Gilda, este é o filme anti-heróico por excelência, cujo personagem principal, um intelectual de posses, colecionador de obras de arte. Nas palavras da entrevistada, o filme trata "daqueles momentos em que se sabe que algo de 
[1] Os três ensaios mencionados neste parágrafo foram incluídos no livro de Gilda de Mello e Souza,Aidéia e o figurado (São Paulo: Duas Cidades/Editora 34, 2005).

[2] Partes deste artigo desenvolvem os pontos principais da apresentação que fiz ao livro Oespirito das roupas, de Gilda de Mello e Souza, no seminário As Ciências Sociais em São Paulo: Obras Decisivas, promovido pelo decisivo vai ocorrer em breve - eque, por isso mesmo, seéforçado a passar de um patamar a outro, quando então somos tomados pela rememoração de acontecimentos importantes da nossa vida pessoal". Em síntese, é uma "meditação final sobre uma vida que está se extinguindo". A do diretor e a do personagem principal do filme. Marcado pelo sentimento da morte e pela consciência infeliz do intelectual num mundo de escolhas políticas, o professor adere a valores cada vez mais em desuso no mundo atual: da maneira como recebe as visitas à noção que tem de intimidade como um domínio quase sagrado.

Noção que não é só dele. É também de Gilda de Mello e Souza e da geração a que pertencia. Assim, talvez não seja descabido usar a leitura fulgurante de Gilda como uma pista para abordamos alguns aspectos da obra dessa ensaísta extraordinária. A paixão que detecta em Visconti pelas formas da vestimenta é partilhada também por ela, pontuando momentos precisos e preciosos da sua produção intelectual. No caso dos filmes do diretor italiano, ressalta Gilda, "o exterior das pessoas que é dado pela vestimenta - como o exterior da casa que é dado pela decoração - é tão importante quanto a narrativa". Reciprocamente dependentes, a linha narrativa é "acompanhada pela roupa das pessoas e pela maneira de estar dentro delas, pelo comportamento". Notável nesse sentido é o uso que Visconti faz da vestimenta para projetar a personalidade da condessa, interpretada por Silvana Mangano. "Uma personalidade a um só tempo construída com muito bom gosto na roupa e extraordinariamente vulgar, com uma certa baixeza no comportamento pessoal".

Essa atenção apaixonada pelas formas da vestimenta sobressai na obra de Visconti. E também na de Gilda de Mello e Souza. Ela está presente no primeiro trabalho acadêmico de fôlego da autora, $A$ moda no século XIX, apresentado em 1950, e no último ensaio que publicou, "Notas sobre Fred Astaire". Incluído no livro $A$ idéia e o figurado (2005) graças à iniciativa editorial do crítico literário Augusto Massi - que também escreveu a (excelente) orelha -, esse ensaio encerra a produção de Gilda. No decorrer desses 55 anos, ela voltou de muitas maneiras, sempre com paixão e rigor, ao tema das formas e do conteúdo das vestimentas. Ora como chave para leituras renovadas da obra de escritores brasileiros, como no ensaio "Macedo, Alencar, Machado e as roupas", de 1995. Ora como pista e indício indiretos para abordar a produção cinematográfica de diretores importantes, caso do artigo "Variações sobre Michelangelo Antonioni", de $1998^{1}$.

\section{A MODA NO SÉCULO XIX VISTA DE FORMA ENVIESADA ${ }^{2}$}

Gilda tinha 31 anos quando escreveu $A$ moda no século XIX: ensaio de sociologia estética. Apresentado em 1950 sob a forma de tese de doutorado, defendida na então Faculdade de Filosofia, Ciências e Letras (FFCL) da Universidade de São Paulo (USP), sob a orientação de Roger Bastide (de quem a autora era assistente na cadeira de Sociologia I), o 
trabalho e a história da sua recepção dão pano para manga. Sobretudo se, no lugar de nos atermos apenas (o que não é pouco) à apreensão pormenorizada da análise sutilíssima e inovadora que a autora faz da moda, ensaiarmos uma leitura enviesada do livro com o intuito de entrelaçá-lo à situação mais geral das mulheres que, como Gilda, se profissionalizaram na Faculdade de Filosofia, Ciências e Letras.

Simbólica e metonimicamente associada ao universo feminino, a moda ganhou nas mãos de Gilda um tratamento estético e sociológico preciso que, se estava em conformidade com o "espírito científico" vigente na época na Faculdade de Filosofia, Ciências e Letras, dele destoava e se distanciava em muitos aspectos. A começar pela forma de exposição do trabalho. Ensaio sociológico, sem dúvida. Redigido, porém, com aquela prosa apurada de quem domina as manhas da escrita, num momento em que "escrever bem" deixara de ser uma das qualidades essenciais na atribuição de valor intelectual de um trabalho acadêmico. Se hoje o estilo de exposição, a mescla da visada estética e sociológica mobilizada para dar conta de um objeto complexo e multifacetado como a moda, as fontes utilizadas (fotografias, gravuras, pinturas e trechos de romances e crônicas do século XIX)e, sobretudo, a argúcia e desenvoltura da autora no andamento da análise, conferem ao trabalho frescor e atualidade surpreendentes, nem sempre esse conjunto de fatores foi ajuizado dessa maneira. Prova disso é a receptividade discreta no início do decênio de 1950.

Concebido como um ensaio de sociologia estética, à boca pequena o tema da tese de Gilda foi considerado como fútil. Coisa de mulher. $\mathrm{Na}$ hierarquia acadêmica e científica da época, que presidia tanto a escolha dos objetos de estudo como a forma de exposição e explicação dos mesmos, a tese de Gilda constituiu "uma espécie de desvio em relação às normas predominantes"3. "Profana" e "plebéia", a moda, na escala de valore legitimidade atribuídos por esse sistema classificatório, encontrava-se em uma posição diametralmente oposta ao tema da guerra, por exemplo, que Florestan Fernandes escolhera para a tese de doutorado, atividade masculina por excelência, "sagrada" e "nobre"4.

Sinal eloqüente de um duplo constrangimento. De um lado, da assimetria difusa vivida pelas mulheres, no plano das relações intelectuais e institucionais que estavam se construindo dentro e fora da universidade onde Gilda se formara em 1939 e se profissionalizara como professora universitária. De outro lado, do constrangimento decorrente da concepção de sociologia dominante na época.Animada por um "espírito" cientificista, afeita à idéia positivista de pesquisa como sinônimo de análise sistemática da realidade, e "encarnada" de forma exemplar na figura de Florestan Fernandes, ela "expulsou" de seus horizontes, quando não de seus espaços de atuação institucional e de seu universo discursivo, o ensaio e as dimensões estéticas dos fenômenos sociais. A transferência de Gilda de Mello e Souza para a área de Estética e a de Florestan para a cadeira de Sociologia I, no ano de 1954, bem
Programa de Pós-Graduação em Sociologia da USP, em junho de 2001. Agradeço aos organizadores do evento, Leopoldo Waizbort, Luiz Jacksone Fernando Pinheiro, pelo convite e pela oportunidade de discutir o livro em pauta na presença da autora. Nesse evento, Gilda fez um depoimento fascinante sobre o objeto de seu doutorado e sobre sua relação com Roger Bastide. Agradeço ainda, e especialmente, a Mariza Corrêa, pelo incentivo para transformar essa fala em texto (publicado nos Cadernos Pagu, no 22, 2003) e a Sergio Miceli pela leitura aguda, como sempre.

[3] Cf. Souza, Gilda de Mello e. O espirito das roupas, $\mathrm{p} .7$

[4] Não foi por acaso e muito menos por razões intrínsecas às qualidades, inegáveis, da tese de doutorado de Florestan que ele ganhou a "guerra" (quer como objeto de estudo, quer como posição institucional) travada naquele momento na Faculdade de Filosofia, Ciências e Letras de forma às vezes veladas, outras nem tanto, para obter os direitos de sucessão na "linhagem" acadêmica instaurada pelos professores estrangeiros. Com a volta de Bastide para a França, em 1954, Florestan se tornaria o "herdeiro" da cadeira onde Gilda trabalhara até então como assistente e que se converteria, graças à sua atuação, em verdadeira "instituição dentro da instituição”, responsável pela criação da chamada Escola Paulista de Sociologia. Para detalhamento maior da carreira de Florestan e de Gilda (bem como de outros integrantes do círculo 
de juventude da autora), ver o meu livro Destinos mistos: os críticos do Grupo Clima em São Paulo, 1940-68 (São Paulo, Companhia das Letras, 1998). Para uma análise circunstanciada da trajetória e da obra de Florestan, ver: Arruda, Maria Arminda do Nascimento. "A sociologia no Brasil: Florestan Fernandes e a 'escola paulista'. In: Miceli, Sergio (org.). História das ciências sociais no Brasil, São Paulo: Sumaré/Fapesp, 1995, vol. 2, pp.107-231; Arruda, Maria Arminda do Nascimento. Metrópole e cultura: São Paulo no meio século XX. Bauru: Edusc, 2001; e Sylvia Garcia, Destino Impar, São Paulo, Editora 34, 2002. Sobre a relação de Florestan Fernandes e Roger Bastide e as implicações na obra de ambos, consultar Peixoto, Fernanda. Diálogos brasileiros. Uma análise da obra de Roger Bastide. São Paulo: Edusp, 2000.

[5] As implicações dessa oposição na "formatação" das ciências sociais e na vida intelectual brasileira, por extrapolarem oâmbito dessa instituição, vêm despertando a atenção dos pesquisadores nos últimos anos. Nessa direção, conferir os trabalhos de Jackson, Luiz. A tradição esquecida. Os parceiros do Rio Bonito e a sociologia de Antonio Candido. Belo Horizonte: Editora da UFMG, 2002; Ramassote, Rodrigo.Antonio Candido e a construção social da crítica literária moderna na USP. São Carlos, monografia de conclusão de curso apresentada à Universidade Federal de São Carlos, 2003; e Schwarz, Roberto. "Saudação a Antonio Candido". In:Antonio Candido \& Roberto Schwarz: a homenagem na Unicamp, Campinas, Editora da Unicamp, 1988, pp. 9-23. Leopoldo Waizbort, em trabalho ainda inédito centrado na análise densa e bastante sofisticada da obra literária de Antonio Candido, achou por bem não deixar de lado as implicações produzidas pela concepção de sociologia no trabalho e na carreira do autor. Mesmo não sendo o ponto central da análise de Waizbort, essa questão aparece sob a forma de um (certeiro) excurso. A seuver, para entendermos a posição e a situação de Antonio Candido nos domínios da cultura e do saber, é essencial compreender o que ele entende por crítica, literatura e história literária e também por sociologia. "Seu trabalho só é, ou deixa de ser, sociologia frente a uma certa sociologia, o que vale dizer que os domínios só ganham identidade contrastiva- como a mudança de Antonio Candido, em 1958, para Assis, após dezesseis anos na cadeira de Sociologia II (antes da sua volta em 1960 para a Universidade de São Paulo, como professor de literatura e não mais de sociologia) são indícios extremamente significativos da oposição entre ciência e cultura que se estabelecera, na época, na Faculdade de Filosofia, Ciências e Letras da USP5.

\section{UM ESPÍRITO FEMININO INQUIETO}

Publicada, de início, numa revista científica habituada a receber colaboração muito diversa, a tese de Gilda teve que esperar mais de mais de trinta anos para vir a público sob forma de livro (numa edição caprichada, com o sugestivo título de Oespirito das roupas) e para ganharo reconhecimento intelectual devido ${ }^{6}$. Em parte, de um lado como resultado da ampliação de temas e objetos considerados "legítimos" no campo das ciências humanas, promovida em larga medida pela antropologia, pela sociologia da cultura e pela história das mentalidades. De outro lado, pela constituição de um novo público de leitores interessados na moda como assunto profissional ou objeto de estudos acadêmicos. Esseduplo movimento, somado à formação do campo da moda no Brasil, com tudo que ele implica (estilistas, modelos, fotógrafos, revistas, críticos, cursos superiores de moda, estudiosos do assunto), tornou possível a absorção e a legitimação, numa escala mais ampla, do tema estudado por Gilda7. Falar de moda, discutir a moda e escrever sobre a moda, aparentemente deixou de ser assunto intelectualmente frívolo. E, para muitos, virou moda. Daí também a clarividência do trabalho de Gilda. Não para promover uma recepção congelada e acrítica do tema, mas para nos ajudar a mirar, com olhos bem abertos, toda sorte de salamaleques discursivos, simplificações analíticas e exibicionismos mundanos que costumam rondar o universo dos produtores e dos consumidores da moda.

Para analisar a moda como fenômeno estético e sociológico, Gilda escolheu o século XIX, por razões bem fundamentadas. Primeiro porque, não sendo um fenômeno universal, a moda foi por muito tempo um domínio exclusivo da sociedade ocidental, aguçado a partir do Renascimento - com a expansão das cidades e a organização das cortes ${ }^{8}-e$ amplamente revigorado no século XIX. Oposta aos costumes, dependente de um sentimento especial de aprovação coletiva, indissociável da sociabilidade urbana, do desejo de competir e do hábito de imitar, ela vai se alastrar num ritmo vertiginoso, e não por acaso, no século XIX.É nesse momento que a "moda se espalha por todas as camadas e a competição, ferindo-se a todos os momentos, na rua, no passeio, nas visitas, nas estações de água, acelera a variação dos estilos, que mudam em espaços de tempo cada vez mais breves" (p. 21).

É também nesse século que a diferenciação entre os sexos, expressa e experimentada com o auxílio das roupas, dos adornos, dos cosméticos e de tudo o mais que compõe a plasticidade simbólica da moda, atinge 
patamares inusitados, inseparáveis, por sua vez, da competição entre as classes e frações de classe. Com o advento da burguesia, da democracia (que anulou os privilégios de sangue e eliminou as leis suntuárias no tocante ao uso de certos trajes, tecidos e cores que até então tinham sido privilégio e apanágio das elites aristocráticas), de novos espaços de sociabilidade burguesa (como o teatro, a ópera, as festas, os salões), dos grandes magazins (que ajudaram a introduzir a mulher burguesa no espaço público das cidades), da voga dos grandes costureiros e da máquina de costura (que tornou possível a reprodução em série e a popularização das vestimentas), a moda ganha relevância especial e, se bem analisada, funciona como um poderoso meio de apreensão as dimensões sutis e cruciais que conformam o jogo fascinante e impiedoso das interações sociais.

Isso - e muito mais - é revelado no livro de Gilda. Para além das evidências históricas e sociológicas que pesaram na escolha do século XIX, outras, de ordem metodológica, foram decisivas para dar sustentação à trama analítica do trabalho. No entender da autora, voltar-se para um século distante do seu, com o propósito de entender um fenômeno tão intricado e multifacetado como a moda,éa maneira mais acertada de, sem abrir mão da análise de nenhuma das partes, conceder atenção maior às ligações da moda com a estrutura social. Cíclica, volúvel e plebéia, sujeita às vezes a aberrantes demonstrações de mau gosto, a moda, quando vista de longe, com o auxílio do afastamento no tempo, mostranos "até onde a aceitação ou rejeição dos valores estéticos depende das condições sociais" (p.23).

Longe de uma petição de princípio sociológico, é o passo mais acertado para escarafunchar a moda a partir de sua tríplice e simultânea:estética, psicológica e social. Mas antes disso é preciso destacar as fontes utilizadas pela autora, arremate final para alinhavar a escolha do século XIX. Fotografias, pranchas coloridas de moda, documentação pictórica, de um lado; crônicas de jornal, estudos sobre a moda, testemunhos dos romancistas, de outro. Tais são as fontes de informação privilegiadas. As primeiras, por fornecerem um registro visual seguro da moda naquele século, eliminam uma série de dificuldades enfrentadas pelos estudiosos que desbravaram o assunto nos séculos anteriores, quando, na ausência das pranchas e da fotografia, podiam fiar-se apenas nas pinturas, nas gravuras, nos textos escritos e nas "bonecas de moda" como fonte de pesquisa 9 . Com a fotografia, as incertezas quanto à "veracidade" das vestimentas estampadas em quadros e gravuras - se invenções do artista ou retrato fiel das roupas usadas na época - são postas de lado. As segundas fontes, escritas por estudiosos do assunto, como Spencer, Tarde e Simmel (responsáveis pelos estudos sociológicos mais importantes sobre a moda produzidos no século XIX), trazem o estado da arte da questão para dentro do livro. Não sob a forma das costumeiras discussões bibliográficas que acompanham os trabalhos escritos originalmente como teses de doutorado, e sim como fios discretos que a autora mente, mediante processos de autoidentificações e autodiferenciações mútuas". Cf. Waizbort, Leopoldo. $O$ Asmodeu dialético. São Paulo, tese de livre-docência apresentada à Universidade de São Paulo, 2003, p. 65.

[6] Cf. Souza, Gilda de Mello e. O espirito das roupas: a moda no século $X I X$. São Paulo: Companhia das Letras, 1987. O prefácio de Alexandre Eulálio ao livro, intitulado "Pano para manga" e o ensaio de Joaquim Alves de Aguiar, "Anotações à margem de um belo livro" (Literatura e Sociedade, no 4, 1999, pp.129-40) são, salvo engano, os textos mais consistentes produzidos sobre o livro de Gilda no âmbito da crítica literária.

[7] Talvez seja mais que uma simples coincidência que $O$ espirito das roupas tenha sido publicado como livro no mesmo ano em que se fundou o primeiro curso universitário de moda no país, instalado na Faculdade Santa Marcelina em São Paulo, em 1987.

[8] Em Oolharrenascente, o historiador da arte Michael Baxandall mostra, entre muitas outras coisas, que a adoção, no século XV, da cor preta nas vestimentas dos integrantes das cortes foi simultânea à ruptura com o dourado no plano da pintura.A razão para adotar o preto sóbrio, longe de poder ser encontrada em pretensas qualidades internas de cor ou tecido, explicase por critérios eminentemente sociais. Istoé, pelo fato de ter sido adotado pela elite de Nápoles, que tinha como centro de sociabilidade a corte do rei Afonso. Para se diferenciar dos novos-ricos da época, essa elite criou formas de ostentar a riqueza, avessas, por exemplo, à exibição de brocados, cores fortes ou ouro nos trajes. O must da época em termos de vestimenta era o corte enviesado. O "desperdício" de tecido provocado por esse tipo de corte tornou-se um símbolo muito mais eloqüente de distinção social do que o uso de tecidos esplendorosos e dourados, que tinham sido moda até então. Ao relacionar a escolha da cor, dos trajes e dos cortes das roupas com outras dimensões centrais da cultura italiana da época, Baxandall se mune de instrumentos analíticos poderosos para destrinchar o sistema de percepção visual no período. Cf. Baxandall, Michael. O olhar renascente: pintura e experiência social na Renascença. Rio de Janeiro: Paz e Terra, 1991. Outro trabalho importante nessa direção é o clás- 
sico livro de Jacob Burckhardt, $A$ cultura do renascimento na Itália (São Paulo: Companhia das Letras, 1991), publicado em 1860 e citado por Gilda na edição inglesa de 1944

[9] "As bonecas de moda" - segundo Maria do Carmo Rainho (cujo trabalho tem uma dívida intelectual expressa para com o livro de Gilda) eram "manequins de cera, de madeira ou porcelana, dos quais se trocavam as vestimentas de acordo com a estação". Nas cortes, "príncipes e princesas tinham por hábito fazer o intercâmbio dos modelos de roupas vestidas" por meio dessas bonecas. Ao longo do século XVIII, "entretanto, as 'bonecas de moda' vão perdendo a utilidade a partir do aparecimento de gravuras publicadas nos jornais, que logo se tornam uma fonte de informação essencial. Mais econômicas e com maior mobilidade - graças à multiplicação das tipografias - as gravuras de moda rapidamente atingem um público mais amplo, que ia além dos círculos aristocráticos". Cf. Rainho, Maria do Carmo. A cidade e a moda. Brasília, Editorada UnB, 2002, p. 71. vai desfiando no andamento da análise, cujo acerto deriva também da maneira como mobiliza o testemunho dos romancistas, a fonte indireta mais reveladora do assunto.

Balzac, Proust e os nossos romancistas Alencar, Macedo e Machado comparecem em alguns dos momentos de maior acuidade analítica de Gilda. Atentos à "significação expressiva dos detalhes", esses escritores captaram, com requinte descritivo inigualável, o dimorfismo estético que tomou conta do século XIX no domínio da moda e do vestuário. A diferença entre os sexos, materializando-se nas vestimentas, aparece sob duas formas distintas: $\mathrm{X}$ para as mulheres, com a cintura comprimida por espartilhos, $\mathrm{e} H$ para os homens, como terno de fazenda áspera e cores sóbrias. Distintas e complementares, as formas; distintos e complementares os sexos que as trajam. $\mathrm{O}$ modelo é o casal burguês. "O encanto feminino e a determinação masculina não se excluem mutuamente: na verdade, são parcelas que se somam na contabilidade astuciosa da ascensão" (p. 83). Enquanto os homens se cobrem de preto, as mulheres se enredam em cores, sedas, rendas, babados, fricotes, laçarotes, xales e decotes. Com os corpos, movimentos e vestimentas, ao contrariar qualquer racionalidade de ordem prática, elas mostram literalmente quanto o domínio da moda é afeito às intempéries do simbólico e aos imperativos das injunções sociais.

Exercendo uma "verdadeira volúpia de posse à distância" (p. 74), derramando-se na descrição dos trajes femininos, contendo-se no trato da indumentária masculina, os escritores, por sua vez, captam "melhor que ninguém, nos meios elegantes, o acordo da matéria com a forma, da roupa com o movimento, enfim, a perfeita simbiose em que a mulher vive com a moda" (p. 24). Perfeita porque plenamente enlaçada nos constrangimentos sociais e psicológicos derivados do duplo padrão de moralidade que regula a conduta de homens e mulheres naépoca. Deum lado, "uma moral 'contratual', um código de honra originado nos contratos da vida pública, comercial, política e das atividades profissionais"; de outro, "uma moral feminina, relacionada com a pessoa e os hábitos do corpo e ditada por um único objetivo, agradar aos homens" (p.58). Carreira, nem pensar. Casar era a solução: única saída para evitar a condenação e o desprestígio social. Nesse contexto burguês, "o casamento era então uma espécie de favor que o homem conferia à mulher, oúnico meio de adquirir status econômico e social, pois aquela que não se casava era a mulher fracassada e tinha de se conformar à vida cinzenta de solteirona, acompanhando a mãe às visitas, entregando-se aos bordados infindáveis, à educação dos sobrinhos" (p.90).

Restrita aos interesses domésticos, as mulheres se aplicavam com esmero no trato com as roupas. Desde muito cedo. Pois sabiam que a graça, o encanto, a elegância e o frescor eram dos poucos recursos de que dispunham para conquistar um lugar ao sol. Se o casamento era a meta, ao ser contraído, longe de atenuar, ampliava o interesse delas pelas artimanhas da vestimenta. Uma vez que a "graça de trazer o vestido, de exibir 
no baile os braços e os ombros, fazendo-os melhores 'por meio de atitudes e gestos escolhidos' [era] simétrica ao talento e à ambição, exigidos pela carreira [do marido]" (p. 83). Desse viver nos olhos dos outros é que as roupas, os adornos, os cosméticos retiravam a força e a significação. Nesse mostrar-se recusando-se, as mulheres eram especialistas, tentando tirar o máximo partido do mínimo a que estavam confinadas em decorrência dos imperativos implacáveis da dupla moralidade vigente na interação entre os sexos.

Disso dão testemunho os escritores que Gilda utiliza no decorrer da análise. Como Machado de Assis, por exemplo. Citando uma passagem admirável de uma crônica do escritor, centrada na análise do comportamento de nossas elites no Segundo Reinado, Gilda sublinha a "trama intricada de competição". Nela "cada um de nós precisa acrescentar às vitórias pessoais, duramente conquistadas - que [Machado] chama com ironia as 'glórias de plena propriedade' - 'as glórias de empréstimo', isto é, as vitórias dos muitos próximos, que se refletem em nós" (p. 83). E arremata a autora: "a análise dessa curiosa contaminação de prestígio, em que o triunfo da mulher repercute vivamente na posição masculina - evice-versa - representa, aliás, um dos fulcros principais do romance do século XIX, tanto na Europa como no Brasil" (p. 83).

A intimidade de Gilda com o universo literário - adquirida desde muito cedo, como leitora compenetrada e reforçada por meio da longa e decisiva influência de seu primo em segundo grau, Mário de Andrade seria revigorada, no período em que escreveu a tese, pela convivência e troca intelectual intensa com o marido, Antonio Candido (na época também ele às voltas com o século XIX e com a elaboração de Formação da literatura brasileira) e pela orientação que recebera de Roger Bastide, sociólogo interessado em todas as manifestações simbólicas da vida social, entre elas as artes e a literatura ${ }^{10}$. Advém daí um dos trunfos de Gilda, que tanto incomodou Florestan Fernandes. Na resenha que publicou em 1952 na revista Anhembi, ele destaca de início a qualidade da tese de Gilda, para em seguida lamentar a forma de exposição.

Tal como se apresenta, o trabalho da Dra. Gilda de Mello e Souza revela duas coisas. Primeiro: o talento e a extraordinária sensibilidade da autora para a investigação de um fenômeno tão complexo, por causa das diversas facetas de que pode ser encarado e explicado. Segundo, um seguro conhecimento do campo de sua especialização, em um nível que até pouco tempo era raro no Brasil. Essas qualidades se refletem na composição do trabalho, tornando a sua leitura muito amena e instrutiva. Poder-se-ia lamentar, porém, a exploração abusiva da liberdade de expressão (a qual não se coaduna com a natureza de um ensaio sociológico) e a falta de fundamentação empírica de algumas das explanações mais sugestivas e importantes. ${ }^{11}$

Vistas de hoje, as restrições emitidas por Florestan em 1952 são justamente o ponto alto do trabalho. De um lado, o estilo de exposição. De
[10] Sobre o amplo interesse intelectual de Bastide, ver Fernanda Peixoto, Diálogos brasileiros.
[11] Trechos de resenha que Florestan Fernandes publicou na revista Anhembi (dez. 1952, no 25, pp. 13940 , realces da autora deste artigo). Devo a Luis Jackson a indicação dessa resenha. 
outro, a desenvoltura com que a autora transita da sociologia para a estética. Valendo-se, para tanto, não só da habilidade para enlaçaro testemunho dos escritores à argumentação analítica — autoral e sociológica que dá tônus ao livro, como dos olhos de lince para perscrutar as dimensões estéticas do fenômeno em pauta. Pois tendo ligação direta com a divisão sexual e a divisão em classes, nem por isso a moda deixa de ser uma forma sutil de expressão de sentimentos pessoais. Sobretudo daqueles que se ressentem da falta de espaços socialmente legitimados para se expandir. Tal era o caso dos sentimentos da mulher burguesa (ou aspirantes a) no século XIX.

Abandonada em si mesma, na ociosidade e submissão,e

tendo a moda como único meio lícito de expressão, a mulher atirou-se à descoberta de sua individualidade, inquieta, a cada momento insatisfeita, refazendo porsio próprio corpo, aumentando exageradamente os quadris, comprimindo a cintura, violando o movimento natural dos cabelos. Procurou em si - já que não the sobrava outro recurso - a busca do seu ser, a pesquisa atenta de sua alma. Eaos poucos, como o artista que não se submete à natureza, impôs à figura real uma forma fictícia, reunindo os traços esparsos numa concordância necessária (p.100).

Mostrando a complexidade de sentimentos que envolvem a moda, reconhecendo o comprometimento com as injunções sociais e admitindo, de saída, que a "forma é em larga medida sancionada pela sociedade", Gilda não abre mão da análise estética. Pois, a seu ver, a moda é arte sim, e de um tipo especial. Para decifrá-la nessa chaveé necessário a um só tempo intimidade com o objeto em pauta (a tal da simpatia sociológica?) e conhecimento amplo das formas simbólicas expressas em diversos suportes artísticos. Gilda tinha ambos de sobra.

A mais viva de todas as artes, a moda - tal como a pintura, a escultura e a arquitetura - encontra na forma o seu veículo de expressão. $\mathrm{Ou}$ melhor, a moda é forma. Valendo-se da materialidade dos tecidos, o costureiro (ou costureira) enfrenta desafios análogos aos dos artistas em geral, ao lidar com as seguintes dimensões estéticas: forma e cor. Mas, diferentemente dos demais artistas, seu grande desafio é a mobilidade. Não por acaso uma das últimas dificuldades a serem resolvidas na história do vestuário. De um lado, por injunções sociais: durante muito tempo, a roupa hirta - incômoda aos olhos de hoje - era símbolo de distinção social: "prova visível, oferecida a todos, de que o portador, não se dedicando aos trabalhos manuais, desprezava o desembaraço dos membros e o conforto das vestes" (p. 48). De outro, por constrangimentos internos à feitura das vestimentas. Muito pano para manga foi gasto para chegar, por exemplo, à simplicidade do vestido cavado em estilo tubinho.

Diferentemente de outras artes, a vestimenta, como mostra Gilda, só se completa no movimento. 
Arte por excelência de compromisso, o traje não existe independente do movimento, pois está sujeito ao gesto, e a cada volta do corpo ou ondular dos membrosé a figura total que se recompõe, afetando novas formas e tentando novos equilíbrios. Enquanto o quadro só pode ser visto de frente e a estátua nos oferece sempre em sua face parada, a vestimenta vive na plenitude não só do colorido, mas do movimento (p.40).

Se assim é, talvez possamos arriscar uma hipótese sobre a relação entre arte, movimento e atrizes, apenas insinuada no trabalho de Gilda. Em nota de rodapé, ela cita Simmel para reter o que convém e duvidar do que the parece pouco acertado:

Em seu ensaio Cultura feminina, Simmel defende o ponto de vista de que a mulheré um ser unitário por excelência, faltando a ela "essa qualidade tão masculina de manterintacta a essência pessoal mesmo quando se dedica a uma produção especializada, que não implica a unidade do espírito". Cada uma das atuações da mulher, ao contrário, "põe em jogo a personalidade total e não separa o eu dos seus centros sentimentais". Daí realizar-se plenamente apenas nas artes do espaço, como a arte teatral, onde efetua a imersão integral da personalidade toda na obra ou fenômeno artístico. Contudo pergunta-se Gilda - até onde esse temperamento unitário será fruto de fatores sociais.? ${ }^{12}$

A indagação é absolutamente pertinente e será respondida com maestria não só no restante da nota, como no decorrer do capítulo em pauta - não aleatoriamente portador do mesmo título, Cultura feminina, do ensaio de Simmel. Certa na observação mais geral, Gilda deixou de lado a hipótese mencionada acima, embora me pareça repleta de sentidos a equação entre sociabilidade urbana + desejo de imitação e de distinção + moda + arte do movimento + teatro + atrizes + a arte do espaço. Se o teatro é um dos campos de produção simbólica que mais conferiram notoriedade às mulheres que dele participam na condição de atrizes, há algo a ser explorado no fato de as atrizes se notabilizarem na arte do espaço e, ao mesmo tempo, na maneira desenvolta e desimpedida como portam os trajes e as vestimentas das personagens. Basta lembrar, para tanto, que no século XIX e em boa parte do $\mathrm{XX}$, antes do advento e supremacia do cinema, eram as atrizes de teatro as principais responsáveis pela difusão de novas modas. "Coquetes e plebéias", elas estão para a moda assim como sua atuação no espaço teatral está para o movimento que a vestimenta exige para se completar como arte.

Se o movimento que confere vida à vestimenta é, a princípio, disponível a todos - pois basta usar uma roupa para que ela se movimente - nem todos conseguem o plus que a singulariza e diferencia

[12] Citação retirada da nota 31, do capítulo 3 do livro de Gilda, p. 229 , realces adicionais da autora deste artigo. 
[13] Conferir, nessa direção, o ensaio deSimmel,Georg. "La moda”.In:Sobre la aventura: ensayos filosóficos. Barcelona: Ediciones Península, 1988, pp. 26-55. os seus portadores dos demais. Isto é, a elegância, definida por Gilda como "elo de identidade e concordância" que se estabelece entre a vestimenta e a pessoa. Claro que para adquiri-la o dinheiro ajuda, como bem sabem os novos-ricos. Mas não basta. Como sabem também os bem-nascidos, que transformam o aprendizado prolongado (sob a forma de habitus) da elegância numa segunda natureza. Elegância que, por ser visível e estampada nos movimentos e nas roupas dos bemnascidos e elegantes, pode ser copiada pelos que não pertencem ao círculo imediato dos privilegiados. Daí o movimento espiralado da moda. Uma vez adotada pelos "mais iguais" entre os "iguais" (isto é, pelos distintos círculos de elite), tende a ser imitada pelos que estão "abaixo" (as classes médias) e pelos "muito abaixo", que, sequer chegam a incomodar os "iguais" dos "muito acima", mas que são um problema e tanto para os que estão medianamente "abaixo". Nessa busca incessante de diferenciação, exacerbada pela vida urbana e pela democracia que aboliu os privilégios de sangue, a vestimenta se torna o "sinal mais eficaz de inferência direta sobre o próximo". Mas essa mesma "democracia que não estabelece barreiras nítidas entre as classes inventa um novo suplício de Tântalo: permite que as elites usufruam uma moda que a classe média persegue sem jamais alcançar e que os pequenos funcionários e todos os párias sociais espiam nas vitrinas com o olhar sequioso" (p. 141).

Apreendendo a moda como objeto complexo, um "todo harmonioso mais ou menos indissolúvel", com múltiplas serventias - "serve a estrutura social", "reconcilia o conflito entre o impulso individualizador de cada um de nós e o socializador", traduz uma linguagem artística, "exprime idéias e sentimentos" (p. 29) -, Gilda dá ao assunto a dimensão espiralada que lhe é própria ${ }^{13}$. Ou seja, inicia o ensaio de sociologia estética pela abordagem da moda como arte, passa pela ligação da moda com a divisão de classes, detém-se na ligação da moda com a divisão entre os sexos, revira pelo avesso a cultura feminina e fecha o livro com o "mito da borralheira". Exemplo vigoroso da profusão de achados analíticos que podem ser garimpados nessa sociologia da festa, o capítulo final mostra como as festas adquirem um "caráter de cerimonial de iniciação, onde entram em jogo mais as qualidades pessoais de cada um que os atributos de sua classe" (p. 166). Espaços de peneiramento e reorganização das elites, as festas são, ao mesmo tempo, momentos privilegiados paro exercício pleno do jogo de sedução entre os sexos - pautado, não nos esqueçamos, pela dupla moralidade própria do século XIX. Nelas, os adornos, as roupas e os gestos ganham, junto com as maneiras e os modos dos portadores, significação máxima na interação social. Sem eles e terminada a festa, alguns voltam à condição de borralheira, outros permanecem onde estavam e alguns, poucos, triunfam, "nessa longa cadeia de provas que [lhes] vão sendo antepostas e cuja vitória final há de conferir aos neófitos a cidadania na classe mais alta" (p.166). 
O último ponto que gostaria de abordar aqui diz respeito a um aspecto menos evidente do livro de Gilda, mas que me parece central para entender a sua força: a maneira como a experiência complexa das mulheres da geração dela, que inventaram para si mesmas um destino para o qual não haviam sido preparadas se introduz no trabalho da autora. Migrando do registro biográfico para dar suporte à empreitada analítica, essa experiência será indiretamente abordada no final do terceiro capítulo, centrado na análise da cultura feminina. Para arrematar o capítulo, Gilda puxa um fio discreto e arma uma trama nova, deixando entrever as marcas decisivas do reprocessamento da experiência social no trabalho intelectual. Vejamos como isso acontece.

Após mostrar que as mulheres, no século XIX, desenvolveram ao infinito as artes relacionadas com sua pessoa, criarndo um estilo de vida que se expressava simbolicamente por meio da moda, Gilda chama a atenção para a experiência das mulheres que embaralharam esse esquema dualista. Entre elas, as suffragettes, que, aspirando a uma existência diversa e vendo na carreira uma fonte de realização pessoal, obrigavam-se ao desinteresse pelo adorno, pela vestimenta rebuscada, pela preocupação com a moda. Mas, nas palavras de Gilda, "não se desiste impunemente de velhos hábitos que anos de vida bloqueada desenvolveram como uma segunda natureza" (p.106).

Lançando-se no áspero mundo dos homens, a mulher viu-se, segundo a autora,

dilacerada entre dois pólos, vivendo simultaneamente em dois mundos, com duas ordens diversas de valores. Para viver dentro da profissão adaptou-se à mentalidade masculina da eficiência e do despojamento, copiando os hábitos do grupo dominante, a sua maneira de vestir, desgostando-se com tudo aquilo que, por ser característico do seu sexo, surgia como símbolo de inferioridade: 0 brilho dos vestidos, a graça dos movimentos, o ondulado do corpo. Ese na profissão era sempre olhada um pouco como um amador, dentro do seu grupo, onde os valores ainda se relacionavam com a arte de seduzir, representava verdadeiro fracasso. Não é de se espantar que esse dilaceramento tenha levado a mulher ao estado de insegurança e dúvida que perdura a té hoje. Pois perdeu o seu elemento mais poderoso de afirmação e ainda não adquiriu aquela confiança em si que séculos de trabalho implantaram no homem (p.106).

Essa longa citação é para mostrar que, embora a autora esteja abordando a experiência das suffragettes, é também dela e das mulheres da sua geração que está falando. Ou seja, das mulheres que, como ela, experimentaram uma transição de modelos de comportamento, procurando novas formas de expressão simbólica da feminilidade, ao mesmo tempo em que se lançaram profissionalmente em carreiras até então consideradas masculinas. Por essa razão, elas viveram por inteiro um momento 
[14] Trechos do depoimento que Gilda de Mello e Souza fez na USP, em julho de 1984, por ocasião da 36 a Reunião da SBPC e por iniciativa do Centro de Estudos Rurais que promoveu o encontro A Mulher nos Primeiros Tempos da Universidade de São Paulo. Transcrito no artigo de Blay, Eva e Lang, Alice Gordo. "A mulher nos primeiros tempos da Universidade de São Paulo", Ciência e Cultura, no 36 (12), dez.1984, p. 2137. Para uma análise exaustiva da situação das mulheres na Faculdade de Filosofia, Ciências e Letras, ver Trigo, Maria Helena Bueno.Espaçose tempos vividos: estudo sobre os códigos de sociabilidade e relações de gênero na Faculdade de Filosofia da Usp (1934-1970). Tese de doutorado apresentada ao Departamento de Sociologia da Universidade de São Paulo, 1997.

[15] Trechos do depoimento de Gilda de Mello e Souza, p. 2137..

[16] Idem. fecundo e simultaneamente doído de transição social no domínio que hoje se convencionou chamar de gênero. O acesso à formação intelectual que tiveram na Faculdade de Filosofia, Ciências e Letras, somado à vivência inédita de uma sociabilidade bastante ancorada na vida universitária, permitiu a várias delas reorientar o papel social para o qual tinham sido educadas: mães e donas de casa. O impacto dessa experiência renovadora propiciada pela faculdade foi enorme, sobretudo para aquelas que efetivamente tentaram inventar para si um novo destino, como foi o caso de Gilda. Mas isso se deu à custa de conflitos, inseguranças e dilemas muito específicos.

Relembrando, em outra ocasião, o tempo de estudante, Gilda afirmou que

vivia dilacerada entre o estilo tradicional da casa que me recebia, da família, do grupo que eu começava lentamente a abandonare o apelo da nova vida [....] $\mathrm{O}$ vento da rebeldia varreu rapidamente tudo: crenças, hábitos piedosos, estilo de vida, fita de Filha de Maria, tudo foi, enfim, mesmo as banalidades das antigas distrações. Só havia no meu horizonte o interesse pela faculdade. A revelação das aulas e o encantamento do novo convívio, aquela nova maneira de ser que estava se desenhando ali, que eu ainda não sabia bem no que ia dar ${ }^{14}$.

O apelo de uma sociabilidade universitária, a sensação inquietante de estar, senão na contramão, a léguas de distância do destino socialmente esperado e previamente traçado para as mulheres de sua classe social, o dilaceramento produzido pelo ir-e-vir entre dois estilos distintos de vida, um tradicional e outro mais arrojado, que não lhe conferia ainda as insígnias públicas de aprovação e reconhecimento — tudo isso, somado, contribuiu para gerar uma profusão de sentimentos tumultuados. Nas palavras de Gilda, "não se pode abandonar assim, do dia para noite, os velhos hábitos pelos novos, sem sofrer muito e sem sentimento de culpa"15.

Decorrentes não só de uma experiência individual, esses sentimentos foram ganhando forma em meio às interações intelectuais e pessoais que então tiveram lugar na Faculdade de Filosofia, Ciências e Letras. Em parte, como resultado da visão escandida que os colegas tinham sobre as reais potencialidades intelectuais das colegas. "No fundo, eles não acreditavam muito na vocação nossa de mulheres, na nossa vocação intelectual". Não é de espantar, então, sintetiza Gilda, "que a opinião agressiva dos grupos conservadores que nós tínhamos abandonado, e a opinião ambivalente e flutuante de nossos colegas tenham contribuído para a elaboração de um ser frágil, tímido, dividido entre a revolta e o medo, o desejo de afirmação e a dolorosa consciência do empecilho"16.

A argúcia com que Gilda em $O$ espírito das roupas reconstrói a vivência e, em certo sentido, a posição em falso e cambiante das suffragettes, que despontaram na cena política, tem a ver, portanto, com a 
maneira discreta com que mobiliza e converte a própria experiência em chave sutil de inflexão analítica. Por meio de um "olhar de esguelha"17 - que outra escritora, Vilma Arêas, já detectara na ficção da autora - Gilda aproxima experiências distintas de mulheres diferentes: das suffragettes, diretamente, e dela e de sua geração, indiretamente. Dessa aproximação, sobressaem os traços mais abstratos que contornam a ambivalência funda que as singulariza. Maneira inesperada de introduzir a relação sujeito-objeto sem o enquadramento metodológico usual que essa relação costuma receber nas teses de doutorado. No lugar de pôr um ponto final na análise da cultura feminina tal como expressa no século XIX, Gilda abre com a questão da ambivalência um novo campo de debate refratário a enquadramentos simplistas e polaridades redutoras.

O reprocessamento da experiência de transição vivida pelas mulheres de sua geração permite a Gilda, como autora, uma lucidez particularmente aguda em relação aos meandros da chamada culturafeminina, vista sempre em relação e conexão com o universo masculino. Daí, sem dúvida, o fato de o alcance analítico de O espírito das roupas ser maior e bem mais intrigante do que várias das análises feitas, anos depois, sobre a chamada condição da mulher.

Aprisionada à lógica simplista de algozes e vítimas, uma parte da produção feminista dos anos de 1970 e 1980 não foi capaz de perceber, e menos ainda de aprofundar, aquilo que Gilda, de maneira discreta, quase sem alarde, detectou como resultado da ambivalência vivida pelas mulheres. Apreendendo a moda como linguagem simbólica, apta a dar plasticidade e expressão a idéias e sentimentos difusos, e não só como meio de marcar pertencimentos e sublinhar distâncias e distinções sociais, Gilda mostrou, muito antes da voga dos estudos de gênero, que as sociabilidades distintas de homens e mulheres no século XIX (mas não apenas nele) só podem ser entendidas como resultado de um engate simbólico que, por ser estrutural, exige acionar uma análise de tipo relacional.

Advém daí o frescor desse livro, escrito há mais de meio século. Podemos dizer então, e sem medo de errar, que o alcance e a atualidade desse trabalho resultam não apenas da mobilização de instrumentos intelectuais agudos numa prosa precisa e elegante, mas também da transmutação da situação social de transição vivida pelas mulheres da geração da autora numa chave apta a renovar o debate e a reflexão sobre as relações de gênero. Assim, talvez possamos dizer sobre O espirito das roupas o mesmo que Gilda disse sobre outro grande livro da nossa história intelectual:Macunaíma, de Mário de Andrade.

Livro típico de épocas de transição social, que não desejam a volta ao passado, nãosabemo que tem de vire sentemo presente como uma neblina vasta, Macunaíma não deve ser tomado como uma fábula normativa. Ele é antes o campo aberto e nevoento de um debate do que o marco definitivo de uma certeza ${ }^{18}$.
[17] Cf.Arêas,Vilma. "Prosa Branca". Discurso, no 26,1996, p. 26.
[18] Cf. Souza, Gilda de Mello e. O tupi e o alaúde. São Paulo: Duas Cidades, 1979. 
[19] Para uma análise sofisticada dos contos escritos por Gilda de Mello e Souza, conferir o ensaio de Arêas, Vilma.
[20] Cf. Bourdieu, Pierre e Delsaut, Yvette. "Le couturier et sa griffe: contribuition à une théorie de la magie". Actes de la Recherce en Sciences Sociales, no1, 1975, pp. 7-36.

\footnotetext{
[21] Originalmente publicado nesta revista (no 41, mar. 1995), esse ensaio foi incluído no livro de Gilda de Mello e Souza, $A$ idéi e o figurado. As citações feitas no decorrer desse segmento foram retiradas do livro.
}

Aplicadas ao espírito da autora e a seu "espírito das roupas", essa citação nos ajuda a refletir sobre as razões mais sutis e menos evidentes que garantem a força do livro e sustentam sua armação conceitual e narrativa. Sendo menos a marca de certezas e muito mais a incitação ao "campo aberto e nevoento do debate", essas razões são inseparáveis da forma como ao longo do livro se molda e costura o argumento analítico de Gilda em relação à moda e suas ligações com a arte, as classes, os sexos e todas as injunções da vida social. Quero dizer com isso que o conteúdo substantivo da análiseé inseparável da forma como eleé apresentado, ou seja, do ensaísmo e da prosa modernista da autora.

Forma e conteúdo, na escrita de Gilda, aludem também à escritora que ela certamente teria sido se, no lugar da carreira universitária, tivesse perseguido uma das vocações de juventude: a de contista, revelada nas páginas da revista Clima $^{19}$. Mas se isso tivesse acontecido, teríamos ganhado uma escritora e perdido, isso sim, a ensaísta plena, dona de um estilo preciso e desimpedido, a um só tempo clássico e modernista, responsável pelo corte impecável que soube imprimir aos vários objetos culturais e estéticos com que se defrontou ao longo de sua produção intelectual.

Portanto, não é descabido fazer uma analogia enviesada entre $O$ espírito das roupas de Gilda e o estilo de moda lançado por Chanel. Por um desses processos extraordinários de alquimia social, responsáveis pela transmutação vigorosa do valor simbólico do produto, proporcional à raridade do produtor, Chanel conseguiu o trunfo máximo que um criador da moda pode alcançar. Isto é, a "suspensão" do tempo, em um universo onde estar na moda é estar sempre na "última moda", como mostram Pierre Bourdieu e Yvette Delsaut no notável estudo sobre as grifes e os produtores da alta costura francesa ${ }^{20}$.

Por caminhos diversos, Gilda conseguiu a mesma proeza de Chanel, só que no campo intelectual, graças à acuidade analítica com que tratou a moda. A suspensão do tempo na recepção desse livro, que, no lugar de envelhecer, ganhou frescor e atualidade inquietantes, parece ser a contrapartida da manutenção do tempo no andamento da análise. Tanto do tempo das mulheres de elite, às voltas com a moda do seu tempo, quanto do tempo da autora, que, filtrando a experiência social de sua geração, soube converter o tempo em fonte preciosa do trabalho intelectual.

Transitando da história para a sociologia, desta para a antropologia e para a estética, mobilizando fontes diversas e pontos de vista inesperados, Gilda adensou o foco analítico sobre a moda e produziu essa jóia de ensaio estético e sociológico.

\section{O GRAU ZERO DA VESTIMENTA E A DANÇA DE FRED ASTAIRE}

A atenção às formas e aos usos da vestimenta que Gilda descortina nas obras de alguns de nossos escritores mais significativos, seria retomada em 1995 no ensaio "Macedo, Alencar, Machado e as roupas" ${ }^{21}$. Entre a tese de doutorado e esse ensaio transcorreram 45 anos. Mais 
madura intelectualmente, Gilda volta ao tema das roupas com voltagem analítica redobrada e economia máxima de linguagem para esquadrinhar o caminho percorrido pelo erotismo na obra desses romancistas, a partir da maneira como eles "vestiram" os personagens e "falaram" de suas roupas. Enquanto Macedo, no romance Rosa (1849), descreve as vestimentas das mulheres com minúcia documentária, mostrando-se um escritor "empenhado na transcrição do real" (embora "sem imaginação", pontua Gilda), Alencar e Machado, "hábeis em desentranhar do visível a verdade oculta das coisas", revelam os significados das roupas em meio a procedimentos narrativos mais sutis. Em Lucíola (1875) e em especial Senhora (1875), Alencar, "aparentemente frívolo na descrição minuciosa" das vestimentas e adereços femininos, cerca o assunto com "acento pessoal e cálida sensualidade" para "descrever simbolicamente a psicologia" de suas protagonistas. Da acuidade da descrição, sobressai a "simbiose que reduz corpos evestimentas a uma realidade única, palpitante" (p.76).

Em Machado a forma de pinçar o tema das roupas é mais complexa. A começar pela rotação de eixo, do pólo feminino para o masculino. No lugar da atenção detalhista nas roupas femininas, praticada por Macedo e Alencar, ele se volta para a descrição dos trajes masculinos como via de acesso privilegiada para caracterização psicológica e social de seus personagens. Dependente desse "vínculo que une sujeito e vestimenta", a trama narrativa em Machado tem ritmos distintos quando se trata de abordar os usos e significados das roupas para homens e mulheres. "A tarefa que cabe à vestimenta das mulheres é acelerar o impulso erótico através do negaceio constante entre o empecilho da roupa e o desvendamento da nudez" (p. 83). Econômico na descrição dos trajes femininos, Machado "jamais esquece que a sua função básica é destacar o encanto da dona" e, com isso, o erotismo possível na época. A "simbiose" entre o corpo e a roupa na mulher machadiana é "apenas um pretexto para irdescartando aos poucos o inútil excessivo, até reencontrar, des-cobrir a verdade originária" (p. 84).

Mais que qualquer outro escritor da época, Machado compreendeu e mostrou nos romances, principalmente em Memórias póstumas de Brás Cubas (1881), que "o despojamento é sempre o traço definidor do ritual amoroso, que pode ocorrer em duas versões: assumido pela mulher, como oferta simbólica, e pelo homem, como momento preliminar da iniciação" (p. 86). Ao contrário de Alencar, que "transfere a libido para a vestimenta, Machado enfrenta o problema sem subterfúgio" (p. 84). E o faz por meio de sua inscrição, mediada pela forma narrativa, no solo social das interações possíveis entre homens e mulheres no Brasil do século XIX. Distinguindo as funções diversas da vestimenta para homens e mulheres na sociedade da época, Machado evidencia a posição social distinta de ambos. Para os homens, as roupas cumprem "sobretudo um papel civil, definidor de status e instaurador de uma identidade fictícia, mas pacificadora”. 
[22] Cf. Bastide, Roger. "Machado de Assis, paisagista". Revista do Brasil, Rio de Janeiro, 3 a fase, no 29, 1940, pp.3-14. O texto foi republicado com o mesmo título na Revista da USP, no 56, dez.-fev. 2002-2003.

[23] Segundo Bastide, "se na Europa, o poeta pode dizer que 'les yeux des femmes sont des Méditerranée"', os olhos das heroínas de Machado de Assis, olhos verdes, olhos de ressaca, olhos de escuma com reflexos irisados, são feitos da própria cor do oceano que banha as praias do Brasil, guardando em suas vagas o encanto de Yemanjá, o apelo dos abismos, a carícia e a traição". Reproduzido de Bastide, Roger. "Machado de Assis, paisagista", p.199.

[24] Cf. Candido, Antonio. Recortes. São Paulo: Companhia das Letras, 1993, p. 103.

[25] Idem, p.109.
Para as mulheres, a um só tempo "submissas e sequiosas de correspondência afetiva", as roupas são um "auxiliar eficiente do jogo erótico, num momento social instável, ambíguo, de conquistas recentes e aspirações sufocadas" (p. 88).

Advém daí, arremata Gilda, a dificuldade da crítica do período em aceitar "a naturalidade com que Machado de Assis iniciava entre nós o discernimento misterioso e no entanto equilibrado do erotismo" (p. 89). "Viciada pelas asperezas do naturalismo", ela não foi capaz de apreender a dimensão inovadora da abordagem machadiana no plano do erotismo.

Essa leitura desempenada de Gilda faz ecoar a lição aprendida com seu orientador, Roger Bastide, que publicou em 1940 um artigo sobre Machado de Assis destoante do ramerrão corrente da crítica, que teimava em denunciar a ausência da paisagem brasileira na obra do escritor ${ }^{22}$. Com o título, "Machado de Assis, paisagista", o artigo mostra que ela está presente, mas não nos lugares estipulados pelas convenções naturalistas, revelando-se por inteira nos olhos enevoados de Capitu²3.

Artigo capital para Gilda e os companheiros de geração, que naquela altura davam os primeiros passos rumos ao empreendimento que os projetaria na cena cultural da cidade de São Paulo (a revista Clima), o impacto causado pela leitura do texto foi de tal ordem que "marcou uma reorientação na maneira de conceber certos aspectos fundamentais da nossa literatura" 24 . Nas palavras de Antonio Candido, Bastide mostrou que "em Machado de Assis a paisagem está presente de maneira mais poderosa, porque não é enquadramento descrito, mas substância implícita da linguagem e da composição, inclusive como suporte das metáforas. Em vez de procurar o 'tema' foi descobrir o modo de elaborar o discurso, cuja latência mostrou de maneira moderna e forte para o estado da crítica nos anos de 1940"25.

Meio século depois, Gilda mostrou, também de forma definitiva, que o erotismo em Machado é mais sutil e complexo porque, velado pelos constrangimentos sociais da época, só se deixava descobrir no jogo de oferecimento e recusa propiciado pela plasticidade simbólica das roupas.

Atenta aos significados distintos que os nossos romancistas insuflaram às roupas das personagens, Gilda pinçou o jogo sinuoso do erotismo num compasso analítico, interessado em perscrutar as ligações profundas entre forma e conteúdo social. Esse mesmo movimento está presente no ensaio "Notas sobre Fred Astaire", último escrito da autora e fecho do livro $A$ idéia e o figurado. Entre os textos que integram o volume, esse é o único que permanecera inédito. Um dos pontos altos de sua produção intelectual, o ensaio é notável pelo que diz e pela maneira como diz. Nele, o foco é deslocado das roupas e dos adereços 
usados por Fred Astaire (1899-1987) - que a autora considera o maior dançarino moderno - para o significado dos gestos e destes para a reflexão surpreendente sobre o sentido da beleza ou de sua ausência na conformação do artista pleno.A simplicidade do título "Notas sobre..." tem menos a ver com a idéia de apontamentos e muito mais com a busca apaixonada pelas formas depuradas, apreendidas pela ensaísta na dança do "super elegante" Fred Astaire, nos quadros cubistas, na traço a lápis de Seurat.

A adesão à modernidade que Gilda flagra em Fred Astaire revela-se na maneira de cantar, na seleção dos compositores (Cole Porter e George Gershwin), na escolha dos trajes (a casaca preta, a cartola, a bengala, os sapatos pretos de verniz) e, sobretudo, no modo como usa e ajusta o corpo à indumentária - a leveza desentranhada do figurino de gala. Instalado no "grau zero da vestimenta" - sublinhado pelo uso do preto e do branco - Fred Astaire é "um homem ancorado no cotidiano, sem nostalgias nem ressentimentos", que, ao contrário do bailarino tradicional, não "se destaca em nada do que o circunda, não se diferencia na vestimenta, na gesticulação, na dinâmica corporal, na relação com os objetos do cotidiano" (p. 171). Por isso, afirma Gilda, quando ele salta, "é como se não houvesse pernas, pois o que apreendemos é o arabesco das abas da casaca em pleno vôo, a nitidez gráfica do desenho, o preto no branco" (p. 176).

Assim, é possível (e desejável) compará-lo a outros artistas representativos do mundo contemporâneo, como Chanel e Charles Chaplin. A primeira, pela busca das formas simplificadas da vestimenta, o segundo, pelo "poder de transfigurar os objetos com perícia de prestidigitador". Com a diferença de que a magia promovida por Fred Astaire tem uma "dimensão lúdica e realiza uma admirável transposição poética do mundo, fazendo do gesto tradução da metáfora", enquanto a de Chaplin se faz no registro do caricaturista crítico das diferenças sociais, para "sublinhar o lado trágico e chegar à representação do absurdo" (p. 174).

Reduzindo o corpo "a um suporte do gesto, não simbolizando em nenhum momento a beleza muscular e a plástica corporal, como fazem o balé clássico e Gene Kelly" (p. 172), Fred Astaire libera e, ao mesmo tempo, encena a "beleza do gesto - pura, livre, autônoma e descarnada" (p. 172). Nessa química paradoxal, uma vez que a beleza projetada pelo artista moderno só se manifesta integralmente quando esbate o suporte corporal, reside a genialidade desse dançarino. Nas palavras de Gilda,

Fred Astaire é um dos poucos gênios artísticos do século XX e foi bom que não fosse bonito, como Robert Taylor, Clark Gable, Gary Cooperou Tyrone Power, porque, sendo como era, manteve-se gesto, gesto puro, graça pura, libertandose dos cacoetes da mocidade para se tornar na dança um desenhista, um dançarino gráfico, puro arabesco sem cor (p. 177). 
Recebido para publicação

em 25 de fevereiro de 2006

\section{NOVOS ESTUDOS}

CEBRAP

74 , março 2006

pp. 87-105
Nas mãos de Gilda, o gesto puro do dançarino converte-seem escrita plena, liberta ela também dos cacoetes da linguagem acadêmica, para descartar o inútil excessivo e reter o que importa. Nesse caso, a acuidade analítica da autora, que, inseparável de sua paixão pelas formas, entrelaça-se à maneira como se expressou ao longo da vida e "vestiu" os assuntos de sua predileção.

HELOISA PONTES é professora no Departamento de Antropologia da Unicampe pesquisadora do núcleo de estudos de gênero Pagu. 